\title{
KAJIAN SARANA SANITASI DASAR PONDOK PESANTREN AL - FATTAH DI DESA BANJARSARI KECAMATAN BUDURAN KABUPATEN SIDOARJO Eka Anggraini, Imam Thohari, Nur Haidah
}

\begin{abstract}
Basic sanitation in Islamic Boarding School is very necessary to paid attention because of the main problem in Islamic Boarding School as basic sanitation aspects is ineligible. These basic sanitation included clean water supply, trash fill means, wastewater outlet means, latrine means that can be produced various diseases such as, diarrhea, dermatitis, and inhalation congestion. This research as descriptive research with cross sectional approach purposed to recognize on basic sanitation means Al-Fattah Islamic Boarding School in Banjarsari village Buduran District Sidoarjo Regency, where performed assessment toward the conditions of infrastructure such as clean water supply, trash fill means, wastewater outlet means, latrine means. Data collecting done with observation and interview. Data taken then analyzed descriptively.

The result of the research of assessment toward basic sanitation means Al-Fattah Islamic Boarding School included clean water supply gain score $257(71,3 \%)$, trash fill means gain 70 $(50 \%)$, wastewater outlet means gain score $66(47,2 \%)$, latrine means gain score $272(75,5 \%)$. Suggested in order to improving the cleaning frequency in basic sanitation facilities routinely to keep their cleanliness.
\end{abstract}

\section{Keywords : Basic Sanitation Islamic Boarding School}

\section{PENDAHULUAN \\ Latar Belakang}

Pembangunan dibidang kesehatan perlu terus dikembangkan oleh pemerintah dengan melibatkan peran aktif masyarakat termasuk swasta dalam upaya meningkatkan kesehatan lingkungan, kesehatan kerja, sanitasi tempat - tempat umum, sanitasi makanan serta masalah air dan pencemaran udara. Pembangunan kesehatan bertujuan untuk meningkatkan kesadaran, kemauan, dan kemampuan hidup sehat bagi setiap orang agar terwujud derajat kesehatan masyarakat yang setinggi-tingginya, sebagai investasi bagi pembangunan sumber daya manusia yang produktif secara sosial dan ekonomis (Undang - Undang Republik Indonesia Nomor 36 tahun 2009).

Menurut Undang - Undang Republik Indonesia Nomor 36 tahun 2009 tentang kesehatan pada pasal 4 menyebutkan bahwa setiap orang berhak atas kesehatan. Guna memperoleh derajat kesehatan yang optimal diselenggarakan upaya kesehatan (promotif), pencegahan penyakit (preventif), penyembuhan penyakit (kuratif) maupun perbaikan kesehatan (rehabilitatif) yang dilaksanakan secara menyeluruh, terpadu, dan berkesinambungan.

Sanitasi lingkungan adalah status kesehatan suatu lingkungan yang mencakup perumahan, pembuangan kotoran, penyediaan air bersih dan sebagainya (Notoadmojo, 2003).

Departemen Kesehatan telah menyampaikan bahwa sebagian besar pondok pesantren masih memiliki masalah dengan kondisi lingkungan dan air bersih (Haryono, Iswahyudi, dkk, 2008).

Masalah pokok yang dihadapi sebagian besar $(80 \%)$ pondok pesantren yang ada di Indonesia adalah masih rawan sarana sanitasi lingkungan. Sebuah kamar mandi dan WC (jamban) yang seharusnya maksimal dipakai untuk 15 orang, dalam prakteknya dipakai 30 sampai 40 orang. Pengalaman telah membuktikan bahwa secara epidemiologis ada keterkaitan yang erat antara masalah air bersih, sanitasi lingkungan dengan penyakit (Emiria Tunggadewi, Dian, 2004).

Penyakit yang sering diderita santri di Pondok Pesantren Sunan Drajat, Banjaranyar, Paciran, Lamongan adalah penyakit scabies dengan frekuensi kejadian 24 kali (25,55\%), diikuti dengan ISPA dengan persentase $(21,3 \%)$. Penyakit tersebut terjadi rata-rata karena kondisi kebersihan diri santri dan sarana sanitasi dasar yang kurang baik (Aan Adriansyah, Agus, 2009).

Observasi awal yang dilakukan terhadap 6 Ponpes di Kabupaten Lamongan, Jawa 
Timur memberikan kesan bahwa : (1) Banyak diantara para santri yang menderita penyakit kulit Scabies (2) Sanitasi Ponpes yang kurang memadai (3) Higiene perorangan yang buruk (4) Pengetahuan, sikap, dan perilaku para santri yang kurang mendukung pola hidup sehat (5) Serta pihak manajemen kurang memberikan perhatian pada masalah sanitasi lingkungan Ponpes (Ma' rufi, Isa, dkk, 2005).

Dalam perkembangan pendidikan Islam Indonesia, pesantren dikenal sebagai lembaga pendidikan Islam tertua. Lembaga ini lahir dan berkembang karena tuntutan dan kebutuhan zaman. Menurut Mastuhu (1994:55) dalam Syamsuhada (2004), pesantren adalah lembaga pendidikan "tradisional" Islam sebagai tempat untuk mempelajari, memahami, mendalami, menghayati, dan mengamalkan ajaran Islam dengan menekankan pentingnya moral keagamaan sebagai pedoman perilaku sehari-hari.

Pondok Pesantren Al - Fattah memiliki santri sebanyak 300 orang. Jumlah kamar yg tersedia di seluruh asrama secara keseluruhan hampir terisi penuh oleh santri. Ukuran luas masing- masing kamar ratarata $36 \mathrm{~m}^{2}$ dan diisi $25-30$ ( $\pm 1,5 \mathrm{~m}^{2} /$ orang) santri, sehingga tingkat kepadatan penghuninya cukup tinggi. Standart kamar yang baik adalah $\pm 4 \mathrm{~m}^{2}$ untuk 1 orang (Santoso, Buddy, 2012). Selain itu, dari hasil survey pendahuluan jumlah penghuni yang banyak juga memudahkan penularan berbagai penyakit berbasis lingkungan, dengan ditemukannya tumpukan sampah di belakang kamar asrama santri. Apabila sampah-sampah tersebut diterpa angin dan terkena air hujan bisa menjadi sarang vektor penyakit serta binatang pengganggu seperti : nyamuk, kecoa, dan tikus. Disamping itu tumpukan sampah tersebut menimbulkan bau yang tidak sedap. Selain itu, Penyakit yang pernah dialami oleh para santri pada 3 bulan terakhir, yaitu: sesak nafas, diare, dan penyakit kulit (gatal-gatal).

Dengan adanya permasalahan yang ada di pondok pesantren Al-Fattah maka perlu diadakan penilaian sanitasi dasar di pondok pesantren Al - Fattah. Hal ini dilakukan untuk mengetahui dan menggambarkan bagaimana kondisi sanitasi dasar pondok pesantren tersebut. Diharapkan nantinya dapat digunakan sebagai acuan dalam memperbaiki dan menciptakan kondisi lingkungan di pondok pesantren yang bersih dan sehat. Tujuan dari penelitian ini untuk mengetahui keadaan sarana sanitasi dasar Pondok Pesantren Al-Fattah di Desa Banjarsari Kecamatan Buduran Kabupaten Sidoarjo Tahun 2013.

\section{METODE PENELITIAN \\ Jenis Penelitian}

Jenis penelitian ini merupakan merupakan penelitian cross sectional, karena penelitian dilakukan dengan satu kali pengamatan dalam jangka waktu tertentu (Soekidjo, 2010:40).

\section{Lokasi dan Waktu}

Lokasi penelitian di Pondok Pesantren AlFattah, Penelitian ini dilaksanakan pada bulan Februari - Juli 2013.

\section{Obyek Penelitian}

Obyek dalam penelitian ini yaitu sarana sanitasi dasar Pondok Pesantren Al-Fattah yang meliputi : sarana penyediaan air bersih, sarana pembuangan sampah, sarana pembuangan air limbah, sarana pembuangan kotoran manusia (Jamban).

\section{Variabel Penelitian}

Dalam penelitian ini variabel yang diteliti adalah sarana sanitasi dasar yang meliputi : sarana penyediaan air bersih, sarana pembuangan sampah, sarana pembuangan air limbah, dan sarana pembuangan kotoran manusia (jamban).

\section{Prosedur Pengumpulan Data}

Terdiri dari data primer yaitu data yang dikumpulkan langsung oleh peneliti dengan melakukan berbagai kegiatan, yaitu : observasi, dan wawancara dan data sekunder yaitu data yang diperoleh dari instansi terkait yaitu profil Pondok Pesantren.

\section{Metode Analisis Data}

Data yang telah diperoleh kemudian diolah dan disajikan dalam bentuk tabel selanjutnya dianalisis secara deskriptif 
Hasil dan Pembahasan

Sarana Penyediaan Air Bersih

TABEL 1

KEADAAN SARANA PENYEDIAAN AIR BERSIH DI PONDOK PESANTREN AL-FATTAH KECAMATAN BUDURAN KABUPATEN SIDOARJO

\begin{tabular}{|c|l|c|c|l|}
\hline \multirow{2}{*}{ No. } & \multirow{2}{*}{ Item Yang Dinilai } & \multicolumn{2}{|c|}{ Hasil Penilaian } & \multicolumn{1}{c|}{ Keterangan } \\
\cline { 3 - 4 } & & Skor & $\%$ & $\begin{array}{l}\text { Kriteria : } \\
\text { Memenuhi syarat jika } 89 \%-100 \%\end{array}$ \\
\hline 1. & PDAM & 111 & $43,2 \%$ & Tidak memenuhi syarat $<89 \%$ \\
\hline 2. & SGL & 146 & $56,8 \%$ & \\
\hline \multicolumn{2}{|c|}{ Jumlah } & $\mathbf{2 5 7}$ & $\mathbf{1 0 0} \%$ & \\
\hline
\end{tabular}

Sumber : Data Primer Hasil Survey di Lapangan

Dari hasil observasi di lapangan didapatkan hasil bahwa untuk sarana penyediaan air bersih diperoleh skor $257(71,3 \%)$ termasuk dalam kriteria tidak memenuhi syarat.

\section{Sarana Pembuangan Sampah}

TABEL 2

KEADAAN SARANA PEMBUANGAN SAMPAH DI PONDOK PESANTREN AL-FATTAH KECAMATAN BUDURAN KABUPATEN SIDOARJO

\begin{tabular}{|c|c|c|c|c|}
\hline \multirow[t]{2}{*}{ No. } & \multirow[t]{2}{*}{ Item Yang Dinilai } & \multicolumn{2}{|c|}{ Hasil Penilaian } & Keterangan \\
\hline & & Skor & $\%$ & \multirow{5}{*}{$\begin{array}{l}\text { Kriteria : } \\
\text { Memenuhi syarat jika } 89 \% \text { - } \\
100 \% \\
\text { Tidak memenuhi syarat < } \\
89 \%\end{array}$} \\
\hline 1. & Konstruksi tempat sampah & 24 & $34,2 \%$ & \\
\hline 2. & Keadaan sarana pembuangan sampah & 12 & $17,2 \%$ & \\
\hline 3. & Periode pembuangan sampah & 30 & $42,9 \%$ & \\
\hline 4. & Cara pembuangan sampah & 4 & $5,7 \%$ & \\
\hline & Jumlah & 70 & $100 \%$ & \\
\hline
\end{tabular}

Dari hasil observasi di lapangan didapatkan hasil bahwa untuk sarana pembuangan sampah diperoleh skor 70 (50\%) termasuk dalam kriteria tidak memenuhi syarat.

Sarana Pembuangan Air Limbah

TABEL 3

\section{KEADAAN SARANA PEMBUANGAN AIR LIMBAH (SPAL) DI PONDOK PESANTREN AL-FATTAH KECAMATAN BUDURAN KABUPATEN SIDOARJO}

\begin{tabular}{|c|c|c|c|c|}
\hline \multirow[t]{2}{*}{ No. } & \multirow[t]{2}{*}{ Item Yang Dinilai } & \multicolumn{2}{|c|}{ Hasil Penilaian } & Keterangan \\
\hline & & Skor & $\%$ & \multirow{4}{*}{$\begin{array}{l}\text { Kriteria : } \\
\text { Memenuhi syarat jika } \\
89 \%-100 \% \\
\text { Tidak memenuhi syarat < } \\
89 \%\end{array}$} \\
\hline 1. & Konstruksi saluran limbah & 30 & $45,4 \%$ & \\
\hline 2. & Keadaan saluran pembuangan limbah & 16 & $24,2 \%$ & \\
\hline 3. & $\begin{array}{l}\text { Sistem pembuangan limbah yang } \\
\text { digunakan }\end{array}$ & 20 & $30,3 \%$ & \\
\hline & Jumlah & 66 & $100 \%$ & \\
\hline
\end{tabular}

Dari hasil observasi di lapangan didapatkan hasil bahwa untuk sarana pembuangan air limbah (SPAL) diperoleh skor $66(47,2 \%)$ termasuk dalam kriteria tidak memenuhi syarat. 


\section{Sarana Pembuangan Kotoran Manusia (Jamban)}

TABEL 4

KEADAAN SARANA PEMBUANGAN KOTORAN MANUSIA (JAMBAN) DI PONDOK PESANTREN AL-FATTAH KECAMATAN BUDURAN KABUPATEN SIDOARJO

\begin{tabular}{|c|c|c|c|c|}
\hline \multirow[t]{2}{*}{ No. } & \multirow[t]{2}{*}{ Item Yang Dinilai } & \multicolumn{2}{|c|}{ Hasil Penilaian } & Keterangan \\
\hline & & Skor & $\%$ & \multirow{3}{*}{$\begin{array}{l}\text { Kriteria : } \\
\text { Memenuhi syarat jika } 89 \% \\
-100 \% \\
\text { Tidak memenuhi syarat } \\
<89 \% \\
\end{array}$} \\
\hline 1. & Jamban leher angsa & 144 & $52,9 \%$ & \\
\hline 2. & Jamban plengsengan /cemplung & 128 & $47,1 \%$ & \\
\hline & Jumlah & 272 & $100 \%$ & \\
\hline
\end{tabular}

Sumber : Data Primer Hasil Survey di Lapangan

Dari hasil observasi di lapangan didapatkan hasil bahwa untuk sarana pembuangan kotoran manusia (Jamban) diperoleh skor $272(75,5 \%)$ termasuk dalam kriteria tidak memenuhi syarat.

\section{Kesimpulan dan saran \\ Kesimpulan}

1. Sarana sanitasi dasar ditinjau dari penyediaan air bersih berdasarkan kualitas yang digunakan memperoleh skor sebesar 257 (71,3\%) yang termasuk dalam kriteria tidak memenuhi syarat.

2. Sarana sanitasi dasar ditinjau dari sarana pembuangan sampah yang digunakan memperoleh skor sebesar 70 (50\%) yang termasuk dalam kriteria tidak memenuhi syarat.

3. Sarana sanitasi dasar ditinjau dari sarana pembuangan air limbah (SPAL) yang digunakan memperoleh skor sebesar $66(47,2 \%)$ yang termasuk dalam kriteria tidak memenuhi syarat.

4. Sarana sanitasi dasar ditinjau dari sarana pembuangan kotoran manusia (Jamban) yang digunakan memperoleh skor sebesar $272 \quad(75,5 \%)$ yang termasuk dalam kriteria tidak memenuhi syarat.

\section{SARAN}

1. Pembersihan sarana pembuangan air limbah (SPAL) secara rutin agar tidak terdapat genangan air, lumut, sampah sehingga kebersihan (SPAL) terjaga dan tidak dijadikan tempat perkembangbiakan vektor.

2. Sarana pembuangan sampah yang tidak memiliki tutup hendaknya diberi tutup agar tidak menjadi tempat perkembangbiakan vektor, dan sampah supaya tidak dibuang begitu saja di lahan kosong, dan sebaiknya berkerjasama dengan dinas kebersihan setempat untuk mengangkut semua sampah apabila sudah menumpuk.
3. Sarana pembuangan kotoran manusia (Jamban) sebaiknya selalu dijaga kebersihannya agar jamban tetap bersih (min tiap 1 minggu sekal dibersihkan), dibuatkan ventilasi yang cukup agar sinar matahari dapat masuk dan ruangan tidak menjadi lembab, dan dilengkapi dengan tempat sampah.

\section{DAFTAR PUSTAKA}

Aan Adriansyah, Agus, 2009. Pengaruh Sanitasi Pondok Pesantren, Higiene Perorangan Dan Kejadian Penyakit Terhadap Prestasi Belajar Santri.

Adnani, Hariza, 2011. IImu Kesehatan Masyarakat. Yogyakarta, Nuha Medika.

Azwar, Azrul, 1995. Pengantar IImu Kesehatan Lingkungan. Jakarta, Mutiara Sumber Widya.

Dinkes Provinsi Jawa Timur, 2012. Tentang Pedoman Teknis Penilaian Rumah Sehat. Surabaya

Kepmenkes RI No.416/MenKes/Per/IX /1990, Tentang Syarat-Syarat dan pengawasan kualitas air.

Kepmenkes RI No.492/Menkes/Per/IV 12010, Tentang Syarat-Syarat dan Pengawasan Kualitas Air Minum.

Margono, 2010. Penyediaan Air Bersih. Surabaya.

Mulia, Ricki, 2005. Kesehatan Lingkungan. Yogyakarta : Graha Ilmu.

Notoadmojo, Soekidjo, 2003. IImu Kesehatan Masyarakat. Jakarta, Rineka Cipta. 
Notoatmodjo, Soekodjo, 2005. Metodologi Penelitian Kesehatan. Jakarta. Rineka Cipta.

Notoadmojo, Soekidjo, 2010. Metodelogi Penelitian. Jakarta, Rineka Cipta.

Notoadmojo, Soekidjo, 2011. IImu \& Seni Kesehatan Masyarakat. Jakarta, Rineka Cipta.

Putro Widoyoko, Eko, 2012. Teknik Penyusunan Instrumen Penelitian. Yogyakarta. Pustaka Pelajar.

Santoso, Buddy, 2012. Kesehatan Lingkungan di Pondok Pesantren. Jawa Timur, Dinas Kesehatan Provinsi.
Sihite, Richard, 2000. Sanitation \& Hygiene (Sanitasi dan Hygiene). Surabaya, SIC.

Suparlan, 2012. Pengantar Pengawasan Hygiene - Sanitasi Tempat - Tempat Umum \& Usaha - Usaha Untuk Umum. Surabaya. Duatujuh.

Suyono dan Budiman, 2010. IImu Kesehatan Masyarakat Dalam Konteks Kesehatan Lingkungan. Jakarta. Buku Kedokteran EGC.

Syamsudduha, St, 2004. Manejemen Pondok Pesantren. Yogyakarta. Graha Guru.

Tosepu, Ramadhan, 2010. Kesehatan Lingkungan. Surabaya. Bintang Surabaya. 